\title{
O CONCEITO DE LEITURA DOS DOCENTES UNIVERSITÁRIOS E IMPLICAÇÕES PEDAGÓGICAS
}

\author{
The Reading Concept of University Teachers and Pedagogical Implications
}

Charlene Soares*

Gildo Volpato $^{* *}$

Almerinda Tereza Bianca Bez Batti Dias ${ }^{* * *}$

\begin{abstract}
Resumo: A formação leitora é intrínseca ao saber e fazer pedagógico, uma vez que a leitura faz parte da constituição dos sujeitos e da docência. O objetivo do presente estudo foi compreender o conceito de leitura dos docentes universitários e as implicações pedagógicas a partir da percepção dos professores. O estudo foi descritivo de abordagem qualitativa, tendo como lócus a Universidade do Extremo Sul Catarinense (UNESC). Participaram quarenta e oito professores. O instrumento de coleta de dados foi o questionário. Quanto à análise dos dados, foram utilizados os princípios da análise de conteúdo de Bardin (2004). O aporte teórico amparou-se nos conceitos de formação de professores abordados por Freire $(2002 ; 2006)$, Cunha (2010a; 2010b; 2012), Nóvoa (1992), Tardif (2002) e Zabalza (2004), dentre outros. Para a discussão acerca da formação leitora, o diálogo ocorreu com Leffa (1996) e Souza (2002), acrescido da contribuição de outros pesquisadores. Identificamos que a formação docente e leitora não é um processo homogêneo e constitui-se por meio da reflexibilidade crítica sobre as práticas pedagógicas e por intermédio da reconstrução contínua da identidade cultural de cada professor. Com relação às práticas pedagógicas, a pesquisa distinguiu que o processo de formação leitora é um fator influenciador nos quesitos de metodologias de ensino aprendizagem também no ensino superior.
\end{abstract}

Palavras-chave: Docentes universitários. Formação leitora. Prática pedagógica.

Abstract: Reading formation is intrinsic to pedagogical knowledge and practice, since reading is part of the constitution of the subjects and the teaching. The aim of the present study was to understand the concept of reading of university professors and the pedagogical implications from the perception of teachers. The study was descriptive with a qualitative approach, having as its locus the University of the Extreme South of Santa Catarina (UNESC). Forty-eight teachers participated. The data collection instrument was a questionnaire. As for data analysis, the principles of content analysis of Bardin (2004) were used. The theoretical support was based

\footnotetext{
* Mestra em Educação e licenciada em Letras - Português, pela Universidade do Extremo Sul Catarinense (UNESC). Profa. do Grupo Educacional (CENSUPEG). ORCID iD: https://orcid.org/0000-0002-8796-2450 - Email: charlene@unesc.net

** Doutor em Educação pela UNISINOS. Prof. no Programa de Pós-graduação em Educação - Mestrado e Doutorado - da Universidade do Extremo Sul Catarinense (UNESC). ORCID iD: http://orcid.org/0000-00019167-7559 - E-mail: giv@unesc.net

**** Doutora em Administração pela UNIVALI. Mestra em Ciências da Linguagem. Profa. nos Cursos de graduação em Letras, Administração e Tecnologia em Gestão da Universidade do Extremo Sul Catarinense (UNESC). ORCID iD: http://orcid.org/0000-0003-3350-0899 - E-mail: bbd@unesc.net
} 
on the concepts of teacher education approached by Freire (2002; 2006), Cunha (2010a; 2010b; 2012), Nóvoa (1992), Tardif (2002) and Zabalza (2004), among others. For the discussion about reading education, the dialogue took place with Leffa (1996) and Souza (2002), plus the contribution of other researchers. We identified that teacher and reader training is not a homogeneous process and is constituted through the critical reflexivity on the pedagogical practices and through the continuous reconstruction of the cultural identity of each teacher. Regarding the pedagogical practices, the research distinguished that the reading formation process is an influencing factor concerning teaching and learning methodologies also in higher education.

Keywords: University professors. Reader training. Pedagogical practice.

\section{Introdução}

Compreendemos que a docência universitária é uma profissão com um amplo campo de saberes específicos e elementos constituintes, em que se entrelaçam a formação humana e o exercício profissional. Dentre esses saberes está a formação leitora como possível elemento constituinte da formação docente e da prática pedagógica dos professores universitários. Tratase de um tema pouco pesquisado no âmbito acadêmico e, portanto, de relevância no campo da Pedagogia Universitária.

O objetivo do presente estudo foi compreender o conceito de leitura dos docentes universitários e as implicações pedagógicas a partir da percepção dos professores. Trata-se de um recorte da pesquisa intitulada "Docência universitária: implicações da formação leitora dos professores na prática pedagógica", realizada no âmbito do Mestrado em Educação, na Universidade do Extremo Sul Catarinense (UNESC), no ano de 2019.

O estudo foi descritivo de abordagem qualitativa, tendo como lócus a Universidade do Extremo Sul Catarinense (UNESC) e a participação de 48 (quarenta e oito) professores da Instituição. Quanto à coleta de dados, foi submetido aos professores universitários um questionário, por meio do Google formulário, no qual os respondentes participaram voluntariamente em conformidade com termo de consentimento livre e esclarecido no próprio instrumento, com dispensa de passar pelo Comitê de Ética da Pesquisa. Quanto à análise dos dados, foram utilizados, para as questões abertas, os princípios da análise de conteúdo de Bardin (2004).

O aporte teórico amparou-se nos conceitos de formação de professores e saberes docentes, abordados por Freire (2002; 2006), Cunha (2010a; 2010b; 2012), Nóvoa (1992), Tardif (2002) e Zabalza (2004), entre outros autores. Para a discussão acerca da formação leitora, dentro de uma perspectiva psicolinguística, o diálogo ocorreu principalmente com Leffa (1996) e Souza (2002), acrescido da contribuição de outros pesquisadores.

Passamos, portanto, ao desenvolvimento do referencial teórico. Inicialmente realizamos uma breve descrição acerca da Universidade e do seu contexto histórico de formação e ensino. Discorremos sobre alguns aspectos da profissionalização docente, como a docência universitária e seus domínios, competências e os saberes docentes. Por fim, apresentamos, amparados em Leffa (1996), entre outros autores, a concepção interacionista de leitura e reflexões acerca dos modelos de leitura top-down, bottom-up e a aproximação interativa. Após, apresentamos os resultados alcançados no presente estudo, sobre o conceito de leitura e o modelo mais utilizado, a partir das análises. Por fim, apresentamos as nossas considerações finais sobre o estudo. 


\section{A docência universitária e os elementos constitutivos da formação}

A docência no ensino superior é um campo de pesquisa que exige ética, coerência e responsabilidade para ser discutida. Conforme as reflexões trazidas por Cunha (2010a; 2010b; 2012), entre outros, percorremos mais de dois séculos de pensamento positivista que influenciam nas experiências com a educação e as representações sociais do contexto educativo. Portanto, as funções, tanto das instituições quanto dos atores sociais, sofrem influências temporais. Tais influências, tanto estruturais quanto tecnológicas, que abrangem os princípios educacionais, segundo Cunha (2010a, p. 09), "exigem saberes e sensibilidades diferenciadas para transitar na complexidade dos processos educativos que respondam as demandas da sociedade e dos educandos."

Segundo Masetto (1998), por influência portuguesa e europeia, no Brasil durante muito tempo contratavam-se os profissionais atuantes no mercado de trabalho que possuíssem maior prestígio na sociedade para lecionar nas universidades. O autor aponta que, até a década de 1970, a exigência para o exercício do magistério no ensino superior era a de que os profissionais possuíssem bacharelado e sucesso em suas carreiras. A justificativa era de que, se os profissionais sabiam desempenhar com qualidade suas atividades, saberiam ensinar, porque o ato de ensinar "[...] significava ministrar grandes aulas expositivas ou palestras sobre um determinado assunto dominado pelo conferencista, mostrar, na prática, como se fazia; e isso um profissional saberia fazer." (MASETTO, 1998, p. 11). Não existia uma preocupação com a qualidade da formação docente nem com as formas metodológicas ou pedagógicas de ensinar. Esperava-se que os alunos ouvindo aulas expositivas e fazendo práticas aprendessem uma profissão. Nota-se que a preocupação com a qualidade da formação docente nem sempre foi exigência no mundo acadêmico. Por isso, refletimos quanto ao cenário educativo no qual esta pesquisa foi desenvolvida, a universidade, que, neste mundo emergente de tudo, luta para manter-se com seus objetivos formativos firmes e estáveis. Para Zabalza (2004, p.09), a universidade é "[...] um espaço de tomada de decisões formativas", pois são nas instituições formativas em que se constituem as identidades profissionais, com a intenção de formar sujeitos capacitados para atuarem nas diversas áreas do conhecimento, aptos a posicionarem-se criticamente frente às questões socioeconômicas e políticas presentes no mundo globalizado.

A profissionalização docente, de acordo com Zabalza (2004), não só ultrapassa os cargos disciplinares por envolver competências relativas à sua mudança e aplicação, como os conteúdos de aprendizagem, como também ultrapassa a condição referente ao processo cuja intenção é a formação. O autor aponta que, cada vez mais, estamos em busca de formações, e neste intuito, pensamos em processos formativos amplos, contemplado a maturidade e a capacidade do compromisso social e ético assumido enquanto docente. (ZABALZA, 2004). Neste sentido, a docência, segundo Masetto (1998, p. 13), "precisa ser encarada de forma profissional, e não amadoristicamente." $\mathrm{O}$ autor afirma isso porque não existe uma formação específica para docência no ensino superior. É sob este ponto de vista que Gimeno Sacristán (1993) retrata que a profissão docente é a expressão da particularidade da atuação dos professores na prática. Segundo o autor, a docência é um conjunto de ações pedagógicas que envolvem os conhecimentos, exercícios, desempenhos, atitudes e valores ligados à prática, que constituem sua identidade profissional. Compreendendo, que o exercício da profissão abrange diversos aspectos, acreditamos, assim como Masetto (1998) e Gimeno Sacristán (1993), que seria importante para a profissionalização docente uma formação específica na área de docência universitária.

Diante do exposto, explicitamos que a docência no ensino superior exige saberes específicos que impactam nos elementos constitutivos da formação docente e no desenvolvimento da prática pedagógica. A posição apresentada por Gimeno Sacristán (1993) 
compartilha desse mesmo pensamento, pois é necessário reconhecer a existência dos saberes específicos à profissão docente. Para o autor, as instrumentalizações próprias das metodologias estão intrínsecas ao trabalho do professor, que não é estático. São os saberes da experiência, das construções diárias, das histórias vivenciadas, que vão fazer cada um encontrar a sua forma de ser professor. Neste sentido, as percepções, as expectativas, os desejos e as necessidades dos professores devem ser considerados, tanto nos momentos formativos, quanto nos avaliativos e nas práticas pedagógicas. Nesta acepção, a formação docente não é estagnada, tão pouco é um processo que apresenta semelhança de estrutura, é transformativo, versátil e mutável. É por isso que Nóvoa (1992) assegura que a "formação" funda-se, também, por meio da versatilidade e destreza das práticas pedagógicas, pela tolerância com relação ao outro, por meio da teoria apreendida com as pesquisas e da reflexão crítica acerca das próprias práticas.

Para Nóvoa (1992), existem três aspectos da identidade do professor universitário, que devem ser considerados: O primeiro é a adesão a princípios e a valores, que se integram na constituição formativa e refletem nas atitudes tomadas e posições assumidas pelos professores dentro das salas de aula, refletindo no ensino. Em segundo lugar, o autor pontua que a ação docente, reflete a postura pedagógica, pois, o professor deve saber escolher as metodologias de ensino utilizadas, porque delas decorrem o sucesso ou o fracasso das experiências, que, por sua vez, marcam a identidade do professor universitário. E o último aspecto, é a autoconsciência, que são as ponderações das ações que formam sua identidade docente e estão relacionadas diretamente ao processo de reflexão sobre sua própria ação didática.

O exercício de compreender a docência e a formação do professor universitário como sujeito da ação pedagógica exige entender que sua essência humana é condicional à sua técnica de trabalho. Os professores, por meio do desenvolvimento de suas capacidades profissionais, cognitivas e afetivas problematizam o ensinar e aprender diante da realidade social, mantendo um posicionamento ético de si e dos outros, comprometendo-se, assim, com a promoção do ser humano em todos os sentidos. "Por isso é tão importante investir na pessoa e dar um estatuto ao saber da experiência." (NÓVOA, 1997, p. 25).

Perante essa reflexão é que passamos a discutir sobre alguns apontamentos acerca dos domínios e competências que condicionam a ação docente no ensino superior. Encontramos, na literatura vigente, requisitos que se configuram em domínios e competências da profissão. Alguns teóricos, como Tardif (2002), Masetto (1998) e Vasconcelo (2000), trazem que dominar os conteúdos teóricos que envolve a área de atuação, a capacidade de colocar o conhecimento teórico em prática e praticar o exercício de manter-se com postura política e ética no ato de ensinar integrado à prática da profissão, constitui-se em uma formação docente de qualidade.

Conforme Vasconcelo (2000), há quatro aspectos da competência profissional, a saber: a formação técnico-científica, que requer domínio técnico do conteúdo que são ministrados aos alunos e dos conceitos relativos às disciplinas da área de atuação de cada professor; a formação prática, adquirida com o tempo de trabalho, por meio das experiências no campo de atuação; a formação política, que trata da educação enquanto ato político, respeitando a concepção de homem e de sociedade e posicionamento ético profissional; e a formação pedagógica, que abrange o processo cotidiano de construção do fazer pedagógico, as formas de atuação, as metodologias adotadas em sala de aula. O conjunto destes aspectos da competência profissional abrangem o processo de construção do saber e do fazer pedagógico.

Os saberes docentes envolvem consciência, reflexão, teoria e prática. De acordo com Cunha (2010b, p. 23), esses saberes "requerem uma base consistente de reflexão teórica que, numa composição com as demais racionalidades, favoreça o exercício da condição intelectual do professor." Nesse mesmo seguimento, Tardif (2002) utiliza o termo "saberes" a fim de 

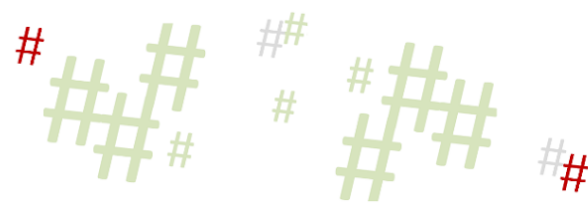

caracterizar as ações, as ideias, pensamentos, juízos, argumentos e discursos docentes, que, por sua vez, obedecem a certas exigências de racionalidade. Nesse sentido, a racionalidade, passa a valer na medida em que as pessoas são capazes de justificar suas ações por meio da razão, isto é, quando há consciência dos atos praticados. Ao conceituar os saberes docentes, Tardif (2002) recorre à importância da racionalidade, compreendida como a capacidade que o professor possui de explicar suas ações pedagógicas.

Para Tardif (2002), os saberes não são conhecimentos empíricos que se esgotam no exercício da docência. São constituídos pelo domínio do conteúdo teórico da profissão que é aprendido no processo formativo inicial, pelo exercício da prática pedagógica, pelo tempo de atividade profissional, pela experiência de mundo. Tardif (2002) considera quatro saberes que fazem parte da constituição da identidade e da formação do professor, a saber: os saberes profissionais, que é o conhecimento científico, que o qualifica como profissional da educação; os saberes disciplinares, que correspondem ao universo do campo do conhecimento e emergem da tradição cultural; os saberes curriculares, que são relacionados aos programas escolares; e os saberes experienciais, que são os conhecimentos do trabalho do professor, de seu cotidiano. Todos os saberes são essenciais e determinantes. Conforme observamos com Tardif (2002), os saberes da docência são base de um círculo de conhecimentos e ações pedagógicas que envolvem tanto os professores quanto os alunos. De acordo com os apontamentos teóricos, a formação docente é parte de um processo de busca permanente, de autoavaliação da prática pedagógica, de transformação e aprendizado contínuo, no qual os professores constroem sua identidade e se reconhecem no mundo.

Diante desse contexto, em uma perspectiva freiriana, acrescentamos que a ação pedagógica é a expressão e o desenvolvimento de atos autônomos, livres e políticos. Conforme aponta o autor, para que possamos alcançar uma educação e uma formação qualificada, devemos nos conscientizar de que, para ensinar e aprender, devemos ter ética, responsabilidade, respeito, consciência e entender que "[...] o essencial nas relações entre o educador e educando, entre autoridade e liberdades, entre pais, mães, filhos e filhas é a reinvenção do ser humano no aprendizado de sua autonomia." (FREIRE, 2002, p. 58). Diante dessa visão, Freire (2002, p. 25) entende que a ação pedagógica não se limita ao fato de "[...] transferir conhecimento, mas criar as possibilidades para a sua própria produção ou a sua construção." Inferimos, portanto, que a docência é uma profissão complexa que exige inúmeras responsabilidades e domínios específicos. A partir desse entendimento, passamos para as reflexões sobre a leitura e a formação leitora no contexto universitário, buscando elementos que possam relacionar o conceito de leitura com as implicações pedagógicas no âmbito da sala de aula.

\section{A leitura e a formação leitora}

Ler é reconhecer e reconhecer-se no mundo no qual estamos imersos. Isto porque vivemos em um mundo letrado e existem muitas formas de ler tudo que nos rodeia. A leitura, a formação leitora e seu ensino contínuo são processos difíceis de serem compreendidos, uma vez que, segundo Solé (1998), lê-se com inúmeras finalidades e com objetivos específicos. Não há uma fórmula precisa para se alcançar à eficácia em leitura e tão pouco para formar leitores proficientes. De acordo com Leffa (1996, p. 10), “[...] não se lê apenas a palavra escrita, mas também o próprio mundo que nos cerca." Para Freire (2006), a leitura do mundo precede a leitura da palavra. Por isso, delimitar ou apontar um conceito de leitura não é uma tarefa simples. Fischer (2006) evidencia que o processo de evolução da leitura influenciou no desenvolvimento das sociedades. De acordo com o autor, quando as pessoas aprendem a ler descobrem um mundo alternativo, descobrem o conhecimento. Neste parâmetro, a leitura é 
entendida também como ato social. Segundo Koch e Elias (2006), Lajolo (1999) e Soares (2004), ler é uma prática essencial à sociedade e o acesso à leitura não deve estar condicionado apenas à elite. A leitura promove, por meio dos leitores assíduos, transformações sociais, pois o que se adquire com a prática frequente da leitura e a problematização que se faz dela influencia nas decisões ou nas tomadas de atitudes no meio em que se vive.

Nesse sentido, consideramos que a leitura envolve, também, os sinais não linguísticos. Para Leffa (1996, p. 10), pode-se ler "a sorte na mão de alguém, uma imagem, uma obra de arte, um filme e até lê-se a tristeza nos olhos das pessoas." Conforme aponta o autor, como ler envolve o sentido da visão, logo, ler, é olhar para uma coisa e ver outra. Segundo Leffa (1996), o processo da leitura não ocorre com o contato direto da realidade observada, e sim por meio da intermediação de outros elementos envolvidos no processo de visão. Valendo-se de uma metáfora, o autor explica que ler seria como ver o mundo por meio de espelhos, "como esses espelhos oferecem imagens fragmentadas do mundo, a verdadeira leitura só é possível quando se tem um conhecimento prévio desse mundo." (LEFFA, 1996, p.10). Então, ler é um processo de representação e interpretação da realidade observada, dependendo da visão que o leitor atribui ao objeto analisado.

Entretanto, a discussão trazida neste artigo é relacionada à leitura do código escrito, o que pressupõe, por parte dos leitores, o domínio da escrita, o exercício da leitura de mundo e a percepção do contexto social, histórico e político que estão inseridos. Estes fatores, entre outros, estão relacionados com a formação contínua dos indivíduos em leitores proficientes e cidadãos críticos. De acordo com Britto (2012, p. 18), devido à "palavra leitura ter seu valor semântico polissêmico, com muitas acepções e aplicações [...]," ganha, portanto, significados variados, de modo que se apresenta e modifica-se de acordo com os seus usos e transformações históricos sociais. O autor aponta que o ato de ler é um processo de decifração e posteriormente ocorre a interpretação. Por isso, configura-se como um espaço de escolhas, de eleição, de negociação de significados, de posicionamento político e de interatividade do leitor com o texto e o contexto.

Diante disso, citamos outros autores que possuem o mesmo posicionamento. Versiani, Yunes e Carvalho (2012, p. 23) entendem "[...] a leitura é um processo subjetivo: compreendemos o código e sabemos contextualizá-lo para dar a ele uma significação, transformando-o em experiência - estamos no âmbito da interpretação, da apropriação do saber." Para Silva (1981, p. 45), a leitura consiste em "compreender a mensagem, compreenderse na mensagem, compreender-se pela mensagem [...]." Segundo o autor, o ato de ler não é apenas um mecanismo de tomada de consciência; é, além disso, "[...] um modo de existir no qual o indivíduo compreende e interpreta a expressão registrada pela escrita e passa a compreender-se no mundo." Neste mesmo sentido, Zilberman e Silva (2004, p. 112) afirmam que "a leitura se coloca como um meio de aproximação entre os indivíduos e a produção cultural, podendo significar a possibilidade concreta de acesso ao conhecimento e agudização do poder de crítica por parte do público leitor."

Para Alliende e Condemarín (2005, p. 171), “[...] um leitor deficiente pode sentir que é um trabalho ler um romance de reconhecida facilidade, porque lhe custa entendê-lo." Segundo os autores, existem três propósitos de leitura: a leitura-estudo que envolve a leitura literária, de modo que ambas visam a atingir objetivos específicos, como é o caso da pesquisa científica, romances, fábulas e contos. São leituras em que o leitor realiza um estudo mais profundo, que é a concepção de ler para aprender. O segundo propósito é a leitura informativa, que compreende a busca geral por informações diversas para abordar os conhecimentos gerais. Esta consiste na busca por instruções variadas, como a leitura de manuais, receitas e de conhecimentos gerais. E a leitura de entretenimento, que é aquela realizada por lazer ou prazer. Esta compreende a leitura dos romances de forma livre, de gibis entre outros. É um tipo de 
leitura mais livre e independente, feita de acordo com a necessidade da informação, com o gosto e o desejo do leitor. Assim sendo, podemos dizer que ambas as leituras são benéficas à cognição dos indivíduos, pois fornecem benefícios específicos, em diversas fases de formação leitora. Não existe uma divisão rígida entre a leitura informativa e leitura de entretenimento. Elas exigem habilidades de leitura e aproximação com o texto.

Podemos considerar, portanto, que a leitura, embora seja o resultado da compreensão do código escrito e da representação de uma língua, não se limita ao processo de decifração. Segundo os estudos sobre linguagem, leitura e escrita dos autores Carrell; Devine; Eskey (1988), Leffa (1996), Rumelhart (1977) e Stanovich (1980), o ato de ler é um processo cognitivo e metacognitivo aprimorado pela prática de leitura e relacionado aos esquemas mentais acionados pela memória. Especificamos que a metacognição, definida por Leffa (1996), é o conhecimento que as pessoas têm sobre seus próprios atos, seus pensamentos, atividades cognitivas e o desenvolvimento das habilidades de controlar esses processos, com o propósito de alcançar seus objetivos. É por isso que, para os autores Leffa (1996), Souza (2012) e Solé (1998), o ato de ler é uma ação humana que envolve as atividades físicas e mentais, estando interligado a subprocessos cerebrais, que estabelecem caminhos de comunicação entre leitor, texto e contexto, relacionado à atribuição de significados e à produção de sentidos. À vista disso, o processo de leitura não é limitado, todavia existem algumas definições para o conceito de leitura plausíveis, que, em suma, explicam o fenômeno da compreensão. Para tanto, elaboramos o quadro-1, baseados em Leffa (1996), que pontua quatro definições de leitura: uma geral; duas definições restritas (que são abordagens ascendente e descendente) e uma definição conciliatória. A saber:

Quadro 1 - Definições de leitura

\begin{tabular}{|c|l|}
\hline & $\begin{array}{c}\text { "Ler é um fenômeno que ocorre quando o leitor, que possui uma série de } \\
\text { habilidades de alta sofisticação, entra em contato com o texto, essencialmente um } \\
\text { segmento da realidade que se caracteriza por refletir um outro segmento. Trata-se } \\
\text { de um processo extremamente complexo, composto de inúmeros subprocessos que } \\
\text { se encadeiam de modo a estabelecer canais de comunicação por onde, em via } \\
\text { dupla, passam inúmeras informações entre o leitor e o texto." }\end{array}$ \\
$\begin{array}{c}\text { (LEFFA, 1996, p. 24) } \\
\text { Abordagem ascendente } \\
\text { (LEFFA, 1996, p. 12). }\end{array}$ & $\begin{array}{l}\text { "Ler é extrair significado do texto," a direção da compreensão é do texto para o } \\
\text { leitor e a centralidade da leitura está na informação do texto. }\end{array}$ \\
\hline $\begin{array}{c}\text { Abordagem descendente } \\
\text { (LEFFA, 1996, p. 14). }\end{array}$ & $\begin{array}{l}\text { "Ler é atribuir significado ao texto," a direção da compreensão é do leitor para o } \\
\text { texto. O destaque da leitura está na atribuição do leitor. }\end{array}$ \\
\hline $\begin{array}{c}\text { Abordagem conciliatória } \\
\text { (LEFFA, 1996, p. 17). }\end{array}$ & $\begin{array}{l}\text { "Ler é interagir com o texto," este é um processo de união das duas definições } \\
\text { restritas de leitura, cujo objetivo é de alcançar uma leitura eficiente. }\end{array}$ \\
\hline
\end{tabular}

Fonte: Elaborado pelos autores com base em Leffa (1996).

Essas abordagens apresentam diferenças no modo em que se interpreta o texto e explicam o que ocorre no processo leitor. Diante do esclarecimento de conceito de leitura abordado por Leffa (1996), passamos a refletir sobre três modelos leitura: bottom-up (processo de abordagem ascendente), a top-down (processo de abordagem descendente), e o modelo de aproximação interativa (processo de abordagem conciliatória), com a pretensão de correlacioná-los com a formação leitora e com o desenvolvimento da ação pedagógica.

\subsection{Modelo Bottom-up: reflexos na leitura e na prática pedagógica}

Bottom-up é uma palavra de origem inglesa, que significa de baixo para cima e, segundo Duran (2009), é um termo utilizado para abordar uma concepção de leitura na qual o leitor analisa a disposição das informações de um texto, tais como estão dispostas. De acordo com 
Duran (2009, p. 04), este modelo abrange o "[...] ato de defrontar-se com o material escrito e decodificar os sinais gráficos, em som articulado, em forma de palavras." Este é um momento de leitura em que o leitor, diante do texto, busca a compreensão fragmentada, como, por exemplo, os significados das palavras desconhecidas nos dicionários. Duran (2009, p. 04) explicita que a compreensão "dá-se de maneira automática, pois, uma vez que o leitor é capaz de decodificar, ele é automaticamente conduzido ao sentido dessa palavra, o que resultaria na imediata compreensão do texto escrito".

Este modelo está dentro da concepção de leitura que envolve o processo de abordagem ascendente, apresentado por Leffa (1996, p. 12), pois, neste modelo “[...] leitura é um processo linear que se desenvolve palavra por palavra. O significado é extraído - vai-se acumulando - à medida que essas palavras vão sendo processadas." A compreensão do texto, neste modelo, é restrito, é imutável, ou seja, o leitor não pode fazer inferências quanto ao material durante a leitura, que o levaria ao verdadeiro sentido de compreender algo. Ele vai apenas decodificar e identificar as informações, sem refletir, porque nesta abordagem, tudo o que contém no texto "[...] precisa ser detectado e analisado para que seu verdadeiro significado possa ser extraído." (LEFFA, 1996, p. 12).

A formação leitora, no modelo Bottom-up, apresenta muitas limitações, para que se possa atingir um nível de proficiência em leitura satisfatório. Conforme os apontamentos de Duran (2009) e Leffa (1996), neste modelo, como o leitor retira significados fragmentados do texto, focalizando a centralidade da leitura no texto, no significado isolado de cada palavra, como se o leitor fosse montando um quebra cabeça ou um mosaico de palavras durante o ato de ler "[...] o raciocínio do leitor é comandado pela informação que entra pelos olhos. O leitor está subordinado ao texto, que é o polo mais importante da leitura." (LEFFA, 1996, p. 13). É assim também para Kato (1990), pois, segundo a autora, o processo de leitura exigirá que o leitor realize operações de análises e síntese ao ler, isso porque o leitor iniciante não possui um vocabulário visual amplo nesta fase.

Quanto à prática pedagógica, é usual os professores elaborarem atividades com questionários para interpretação de textos. Quando são elaboradas tais questões, os professores devem levar em consideração que o texto ou material utilizado para a análise, "[...] não possui um conteúdo, mas reflete-o, como um espelho. Um mesmo texto pode refletir vários conteúdos, como vários textos podem também refletir um só conteúdo." (LEFFA, 1996, p. 13). Duran (2009) cita que se as atividades elaboradas em forma de questionário forem possíveis de ser respondidas com uma leitura superficial, ou nos comandos das questões e as dicas para as respostas são encontradas no texto com facilidade, o leitor não fará uma análise, ou seja, não ocorre a interpretação. "Isso implica em uma não-construção de uma bagagem formada através da leitura, já que a interpretação do texto não é alcançada, caracterizando-se essa leitura como apenas decodificadora." (DURAN, 2009, p. 05). Todavia, de acordo com Duran (2009), esse tipo de metodologia pode ser utilizado em aula, com a intenção de conduzir os alunos "pelas estruturas do texto, identificando elementos explícitos e ajudando-o a encontrar o caminho para a busca de elementos mais difíceis de serem localizados." (DURAN, 2009, p. 05). Logo, o objetivo desse exercício seria de preencher as lacunas identificáveis no texto.

Este modelo de leitura não deve ser excluído da prática pedagógica. Segundo Duran (2009, p. 04), partindo do entendimento de que "as palavras por si só, ao serem lidas, são capazes de transmitir seu significado [...]," enfatiza que este processo privilegia "[...] que o leitor tenha domínio das regras gramaticais, pois é, por meio delas, que ele vai conseguir aproximar-se do texto, uma vez que este, de modo geral, é escrito na norma culta." Diante do exposto, compreende-se a importância da extração dos significados de um texto, entretanto não 
consideramos que esse seja o objeto central de avaliação de uma leitura eficiente. Para ser um leitor proficiente, é necessário buscar por uma leitura reflexiva, de modo que o leitor seja capaz de compreender as informações do texto e não apenas extraí-las. Uma vez que, compreendemos esse modelo de leitura, passamos ao segundo o modelo o Top-down.

\subsection{Modelo Top-down: reflexos no processo leitor e na ação pedagógica}

O termo inglês Top-down, significa de cima para baixo. De acordo com Duran (2009), o modelo Top-down implica em dividir os processos de informação do texto, de forma fragmentada, para tornar a compreensão de cada elemento, que compõem um todo, mais fácil de ser processado pelo leitor. Neste modelo, as partes de um texto são exploradas pelo leitor em parágrafos, ou seja, o texto passa a ser subdivido, para ser compreendido, detalhando as informações, para que se obtenha um entendimento um pouco mais amplo do assunto a ser lido. Neste modelo percebe-se que "ler é atribuir significado ao texto". Conforme afirma Leffa (1996, p. 14), isto ocorre porque a direção da compreensão é do leitor para o texto. O processo de compreensão do material lido, o texto, se propaga na proporção que o leitor vai avançando no texto: "As letras vão formando palavras, as palavras frases e as frases parágrafos. O texto é processado literalmente da esquerda para a direita e de cima para baixo." (LEFFA, 1996, p. 13).

É dentro desse modelo de leitura que se encontra a abordagem descendente, apontada e caracterizada nesta nomenclatura por Leffa (1996). Nesta abordagem, segundo o autor, a centralidade da leitura, possui destaque no leitor, acrescentando que é um processo de atribuição de significados e de conhecimento prévio do mundo que o leitor possui. De acordo com Leffa (1996, p. 14), a "[...] visão da realidade provocada pela presença do texto depende da bagagem de experiências prévias que o leitor traz para a leitura." Entretanto, é relevante salientar que a confiança demasiada em processos descendentes pode causar construções inadequadas de sentido. Desse modo, a leitura para ser considerada eficiente precisa também ser apoiada no texto (CARRELL; DEVINE; ESKEY, 1988). Sendo assim, a “[...] compreensão não é um produto final, acabado, mas um processo que se desenvolve no momento em que a leitura é realizada." (LEFFA, 1996, p. 15).

Assim sendo, a formação leitora, na perspectiva Top-down, é um processo cognitivista, que prioriza que "o leitor é responsável pelo sentido, uma vez que a leitura é permeada por sua bagagem adquirida previamente, pois é acessando essa bagagem que ele atribui significado ao texto.” (DURAN, 2009, p. 06). Segundo Duran (2009), o processo de formação leitora se inicia com a observação e análise do texto, passando a ser estabelecido com o contato inicial junto a ele, a fim de alcançar a compreensão de forma ampla. Leffa (1996) enfatiza que a percepção leitora, neste modelo de leitura, começa a partir da observação do título, das imagens, da identificação do autor. Depois, o leitor começa a atribuir significado semântico às palavras, e a leitura prossegue pelos parágrafos, focando na compreensão de um todo, não de palavras isoladas. Neste momento, Leffa $(1996,1996$, p.15) esclarece que “[...] o leitor levanta uma série de hipóteses e começa a testá-las, desde o nível do discurso até o nível grafo fonêmico, passando pelos níveis sintáticos e lexicais [...]" e que assim o leitor é enfatizado no processo. Para complementar esse pensamento e ressaltar o processo de inferência, Duran (2009, p. 14) nos revela que a responsabilidade para que ela ocorra é "[...] tanto do texto, que oferece as dicas e as pistas para que o leitor o intérprete, quanto do leitor, que aborda o texto no uso de suas bagagens sócio historicamente constituídas que o permitem ler o texto." Dentro desse modelo top-down, cuja abordagem é descendente, os estímulos externos e o conhecimento prévio acionam o que Rumelhart (1977) e Leffa (1996) nomearam de esquemas mentais, acionado, por sua vez, pelas lembranças e pela memória, relatados também nos estudos de Souza (2012). 
Diante desse entendimento, os conhecimentos prévios de leitura e de mundo são acionados pelos estudantes para significar um texto, por isso que os aspectos cognitivos são fatores importantes da formação leitora. É neste sentido que se pode considerar que o ato de ler envolve diversos aspectos das competências humanas que refletem nas práticas pedagógicas e na sociedade.

No que concerne à atuação pedagógica de avaliação em leitura, no processo de ensino e aprendizagem, com o intuito de que os alunos alcancem a compreensão, Duran (2009, p. 07) aponta que "[...] a leitura do aluno é priorizada em relação à leitura que o professor propõe, sem que isso signifique, necessariamente, que a leitura do aluno tenha permissão de esvair-se dos limites impostos pelo texto." Isso ocorre porque a natureza da qual incide pensamentos dos alunos não fazem parte do mundo do professor, existindo uma distância entre a vivência de um e de outro. É por este motivo que o autor diz que medir ou compreender como o leitor chega à compreensão em uma determinada leitura, tanto quanto ao conteúdo explícito quanto ao implícito, tornou-se um objeto de estudo importante na prática pedagógica. "Considerando-se que o texto fornece a matéria a ser lida e a mente do leitor oferece a ferramenta capaz de (mais que decifrar e decodificar) significar a mensagem ali contida, é consequência de nosso raciocínio perceber que isso abre possibilidades para diversas leituras." (DURAN, 2009, p. 07). Em outras palavras, por mais que o aluno possa utilizar-se de sua leitura de mundo, de seus conhecimentos prévios, com relação à leitura de um determinado texto, "[...] não pode fugir do que é possibilitado de se depreender em uma determinada leitura.” (DURAN, 2009, p. 07).

Conforme Duran (2009) e Leffa (1996), cada um desses modelos apresentados são importantes para a constituição de um leitor proficiente; entretanto, notamos que sozinhas não são insuficientes para explicarem o processo de compreensão em leitura e não são capazes de levar o leitor a atribuir sentido e significado ao texto quando são utilizadas individualmente. Por isso, faz-se necessário um processo de interação entre leitor, texto e contexto. Dessa forma, passamos a refletir sobre o modelo de aproximação interativa de leitura.

\subsection{Modelo de aproximação interativa de leitura: contribuições para a formação e o ensino}

A partir de agora apresentamos o modelo interativo de leitura. Segundo Leffa (1996), neste modelo, as abordagens ascendentes e descendentes se unem, complementando-se uma à outra e ocorre um terceiro processo de compreensão o de aproximação interativa, que envolve a abordagem conciliatória, que visa a promover que o leitor alcance a compreensão e a produção de sentidos e significados em um texto. Entretanto, Leffa (1996) enfatiza que não é possível no processo de compreensão, fixar-se em apenas um modelo de leitura, tampouco limitar seus elementos, com exclusão de um ou de outro e nem adicionar só as contribuições do leitor e do texto. De acordo com o autor, a perspectiva interacionista de leitura presume a interação entre leitor, texto e contexto, promovendo dessa forma a compreensão, de modo que leitor e texto reajam entre si. É neste contexto que temos um leitor maduro.

Buscamos compreender o modelo interacionista de leitura, também, por meio dos conceitos abordados por outros pesquisadores, como por Solé (1998). Para a autora, a leitura é um processo no qual se compreende a linguagem escrita, por meio da interação das atividades leitoras, relacionadas aos processos físicos e mentais do leitor, com o material a ser lido e o contexto que envolve o momento da leitura. Na mesma visão, Kleiman (2009) afirma que a leitura aciona os mecanismos de conhecimentos prévios, relevantes à compreensão do texto, atividade que fornece pistas e sugere caminhos; todavia, embora este seja um processo interativo que envolve diversos níveis do conhecimento, como o linguístico, textual e entendimento do mundo, não deixa claro tudo o que seria possível explicitar. De acordo com 

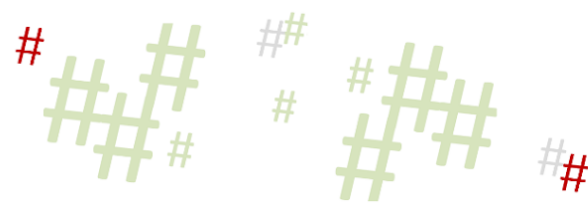

Kato (1990), é por meio da leitura e das inferências realizadas que se acessa e se reveem os significados do código escrito e, entendendo a leitura como uma ferramenta de construção de significados e produção de sentidos, alcança-se a compreensão em qualquer área do conhecimento. Trilhando este pensamento interacionista de leitura, percebemos com Souza (2012) que a leitura efetiva só se concretiza quando existe uma produção de sentidos e significados que o leitor produz ao ler. Segundo a autora, o ato de ler e escrever não são processos independentes; eles são desenvolvidos juntos, pois se escreve para alguém ler e se lê se alguém escreveu. Esta ação humana envolve todos os aspectos físicos e mentais dos indivíduos. Para a autora, "a leitura não apenas promove a aprendizagem como é dependente dela no que concerne às especificidades de uma tarefa relacionada ao caráter tecnológico da escrita." (SOUZA, 2012, p. 39).

No que concerne ao processo de aprendizagem, dentro dessa visão interacionista da leitura, os autores Carrell; Devine; Eskey (1988), Leffa (1996), Rumelhart (1977), Souza (2012) e Stanovich (1980), incluindo os supracitados no parágrafo anterior, partem do princípio de que o conhecimento de mundo, ou seja, o conhecimento prévio que cada indivíduo possui está armazenado no cérebro em unidades chamadas de schemata ou esquemas mentais. Este processo é interligado às nossas lembranças, de acordo com Souza (2012), e cada esquema mental de uma memória reúne informações pertinentes ao conteúdo armazenado, como as imagens, os sons e os odores. E, ainda, agregam as informações que se referem à utilização de cada esquema. Sendo assim, de acordo com os autores, para se obter uma proficiência em leitura é necessário acionar os mecanismos cerebrais, que seriam os esquemas. Para Leffa (1996), Rumelhart (1977) e Souza (2012), tais esquemas são considerados parte de um processo importante da memória, diretamente relacionado à compreensão das situações cotidianas, que se apresentam por meio de qualquer um dos nossos sentidos: visão, audição, paladar, tato e olfato. É neste sentido que Leffa (1996, p. 25) observa que "para compreender o mundo o indivíduo precisa ter dentro de si uma representação do mundo."

Com relação às práticas pedagógicas, quando se pensa na relação do ensinoaprendizagem, seja qual for a competência que estiver sendo atribuída, a autora ressalta que se considere que o cérebro humano se organiza em torno da produção de significados. "Acontece à aprendizagem, quando novo é trazido em relação a conhecimentos prévios do indivíduo em situações motivadoras e que possibilitam a produção e o desdobramento de novos sentidos." (SOUZA, 2012, p. 39). Para autora, não existe tempo ou espaço demarcado para o ato da leitura ou para o seu aprendizado. A leitura parte do desejo do leitor em sem entregar, implicar o seu desejo, juntamente com as múltiplas escolhas e possibilidades existentes no mundo da leitura, no mundo de produção de sentidos e significados que a leitura proporciona na vida de cada um. Acrescenta-se, ainda, que se um dos princípios básicos para aprendizagem, conhecido como hipótese do tempo total, "obedece à regra de que o tempo gasto no aprendizado reflete a quantidade apreendida." (SOUZA, 2012, p. 32). Isso quer dizer que, quando se duplica o tempo de aprendizagem, de acordo com a autora, a quantidade de informações manipuladas e armazenadas também se duplicam, e, com a prática e o exercício do cérebro sendo desenvolvidos, vão se alcançar maiores índices de aprendizagem, passando a contribuir para um efetivo aprendizado de qualidade. Com os apontamentos de Souza (2012), que apresenta questões relativas à memória, aprendizagem e escrita, é possível afirmar que a leitura é um processo interacionista e um instrumento de produção de sentidos e significados e, ainda, que só quando esse processo ocorre é que teremos leitores mais proficientes e um progresso nas questões de ensino aprendizagem. 
A partir desse entendimento, considera-se que, no processo interacionista de leitura, para se alcançar uma compreensão textual satisfatória, os leitores devem possuir capacidade de realizar inferências, desenvolver habilidades linguísticas gerais, acionar suas habilidades de memória e considerar seus conhecimentos de mundo. Percebe-se que essas habilidades, quando juntas, contribuem para a construção de uma representação macroestrutural do texto. Assim sendo, ler envolve a conexão e a interligação de um conjunto de habilidades cognitivas e metacognitivas de um sistema já existente: o processamento da linguagem falada para o processamento da linguagem escrita. A união deles leva a um sistema sofisticado de compreensão do mundo e inferência textual (STANOVICH, 1980). Na próxima seção serão apresentados os resultados das análises da pesquisa de acordo com a percepção dos professores universitários sobre seus conceitos de leitura, correlacionando-os com as práticas pedagógicas e suas experiências.

\section{$4 \mathrm{O}$ conceito de leitura e suas implicações pedagógicas sob a ótica dos professores universitários}

Conhecer as concepções de leitura que os professores universitários possuem é desafiador, quando se pretende relacioná-las à sua formação e sua prática pedagógica. Isto porque cada pessoa recebe uma formação diferente, como visto em Nóvoa (1992), quando ponderamos os três aspectos da identidade do professor universitário, quanto sua adesão a princípios e a valores, relacionadas com a ação docente e autoconsciência. Também quando temos a consciência dos quatro aspectos da competência profissional, discutidas em Vasconcelo (2000), pois a formação técnico-científica pressupõe o domínio técnico do conteúdo ministrado e dos conceitos relativos às disciplinas da área de atuação de cada professor. Além disso, para relacionarmos a formação docente com a formação leitora e as práticas pedagógicas não podemos deixar de ponderar os conceitos de docência abordados por Tardif (2002), porque os quatro saberes docentes fazem parte da constituição da identidade e da formação do professor. Logo, compreendemos que tudo isso está relacionado não apenas ao conceito de leitura, ou a formação leitora, e sim diretamente ao processo de reflexão sobre a própria formação docente e sua ação didática. Dentro desse contexto é que abordamos a questão da formação leitora. Amparados em Solé (1998, p. 21), podemos dizer que a leitura se configura em um "“[...] objeto de conhecimento em si mesmo e como instrumento necessário para a realização de novas aprendizagens." A partir disso, passamos a refletir sobre o que é leitura?

A leitura é um conjunto de ações cognitivas e metacognitivas que levam o leitor a compreensão de um todo, em um processo de interação, que ocorre entre leitor e texto, visando a obter informações para se alcançar os objetivos propostos na leitura. É neste sentido, que Leffa (1996) ensina que ler faz parte de um processo de representação da realidade do mundo no qual estamos inseridos. E a compreensão só é alcançada quando se tem um conhecimento prévio desse mundo. Souza (2012) e Fischer (2006) afirmam que ler é constituir-se um indivíduo crítico, é apreender diversos conhecimentos e atribuir sentidos, para utilizá-los na conscientização, construção e evolução de uma sociedade. Então é direito de todos, e não privilégio de alguns. Sendo assim, a leitura é uma fonte de produção de conhecimentos, sentidos e significados. Podemos afirmar que o conceito de leitura é associado ao processo de formação leitora, que pode ser individual ou coletivo. Tal formação e conceito acompanham o leitor ao longo de sua vida pessoal e profissional. (DURAN, 2009; KLEIMAN, 2009; LEFFA, 1996; SILVA, 1981; SOLÉ, 1998; SOUZA, 2012).

Nesta perspectiva, apresentamos nossas análises quanto aos conceitos de leitura atribuídas às respostas dos professores universitários. Presumimos, de acordo com as análises, 

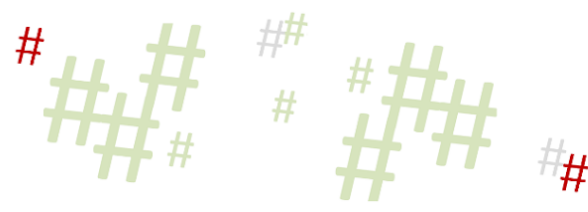

que nos momentos nos quais os professores buscavam em suas memórias as respostas ao questionário realizaram uma autorreflexão quanto ao assunto e suas vivências e práticas cotidianas. Os respondentes expressaram suas opiniões sobre o que entendem por leitura sem recorrer a recursos teóricos, como podemos observar nessa fala "Leitura é todo ato de ler algo, desde uma post em uma rede social até um livro técnico." (R 3). E também, na expressão de que leitura é "debruçar-se sobre um conteúdo que eu gosto de ler. Algo que não seja um pesadelo para fazer." (R 17).

Questionamos se os professores se consideravam leitores, e o que é ser leitor? Segundo os dados da pesquisa, $48 \%$ dos professores possuem uma visão interacionista acerca da leitura, como podemos perceber a partir do conteúdo da resposta de dois participantes: "[...] a leitura só é plena quando o leitor a entende e o entendimento muda ou reforça o modo pelo qual o leitor compreende as coisas." (R 4). Da mesma forma, manifesta-se outro professor relatando que leitura "[...] é o ato de dedicar-se ao entendimento de uma obra, seja ela literária, ou voltada para alguma outra área do conhecimento mais específica." (R 12). De acordo com Leffa (1996), no modelo interacionista, o processo de leitura exige compreensão e interação entre leitor, texto e contexto. Por meio de uma analogia, Leffa (1996) explica que esse processo é igual a uma engrenagem, promovendo a produção de sentidos e significados durante o ato de ler. Conforme Freire (2006), o ato de ler leva o indivíduo a se reconhecer no mundo; logo, entender a leitura de forma interacionista leva o leitor a compreensão, e isso faz com que ele reconheça os vários contextos lidos. Da mesma forma é para Silva (1981), porque a leitura consiste em compreender e compreender-se a mensagem do que se propõe a ler.

Dos quarenta e oito participantes apenas dois disseram que não são leitores. Um deles assim se manifestou: "Não me considero. Ser um leitor é ser uma pessoa que lê livros frequentemente." (R 42). A segunda respondente diz: "Não me considero leitora, pois para me considerar leitora acho que deveria ler muito mais. Fazer uma leitura "conversando com o autor", com um parecer a respeito." (R 48). Para Fischer (2006), algumas pessoas gostam de passar seu tempo lendo, buscando por informações, atualizações ou pelo deleite na leitura. Dessa maneira, aumentam sua criticidade, seus poderes de percepção, persuasão e o vocabulário, outras não compreendem a leitura da mesma maneira. Acreditamos que todo tipo de leitura é válido. De acordo com Souza (2012) e Solé (1998), não é a quantidade da leitura que realizamos que nos faz leitores, e sim a prática de leitura. No exercício da docência, ser leitor influencia diretamente, pois pressupõe-se que o professor, de acordo com Nóvoa (1992), relacione sua identidade com a ação docente e tenha autoconsciência. Logo, conforme Souza (2012), se não somos leitores, não podemos ensinar leitura e esse ensino envolve qualquer área do conhecimento.

Lembramos que, segundo os apontamentos de Leffa (1996) e Freire (2006), a leitura não é apenas uma ação limitada à decifração do código escrito, pois existem infinitas formas de ler tudo que nos cerca no mundo. O professor (R 27) encontra guarida no pensamento de Leffa (1996) e Freire (2006), quando relata que "[...] ler é desvelar um mundo codificado nos códigos linguísticos sistematizados em um texto escrito ou imagético." Para o respondente (R 27), "a leitura amplia o horizonte de compreensão da vida e da compreensão do mundo que nos cerca." Segundo apontamentos de Leffa (1996), a leitura na visão interacionista é um ato cognitivo e metacognitivo e, portanto, é sempre uma forma de aprender. "Independente do que você leia, sempre terá um momento que poderá mudar a sua opinião, amadurecer a sua ideia ou descobrir coisas novas." (R 45). Neste sentido, pensamos na prática de sala de aula, visto que a docência no ensino superior "[...] é uma prática que não se repete, é sempre única. Como tal exige capacidades para enfrentar situações não previstas." (CUNHA, 2010a, p. 11). Pois é, assim, 

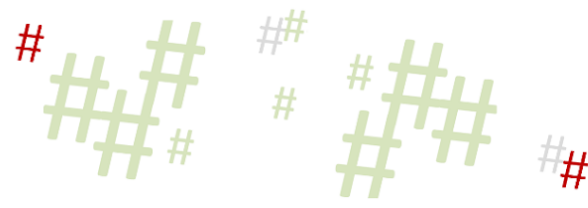

dentro dessa percepção interativa e de compreensão de leitura de mundo e teórica, que o professor, que a possui, alcança autonomia, confiança e segurança, no ato de ensinar.

Dentro deste contexto, a partir da percepção dos professores, passamos a relacionar com os conceitos estudados, o modelo de leitura, com os quais os participantes da pesquisa mais se identificavam para utilizar em sala de aula, com ênfase na aprendizagem significativa. Segundo Gimeno Sacristán (1993), a profissão docente é a expressão da particularidade da atuação dos professores na prática. Neste sentido, com relação à ação docente, percebemos, nas falas dos professores, que eles, possuem visões diversificadas da leitura e seu ensino, na forma que se identificam com ela e a utilizam. Nem todos os respondentes compreendem a leitura como uma ferramenta de trabalho. Em suas declarações, percebemos que se posicionam como leitores, mas não atribuem que a leitura efetiva e seu ensino é a chave para a compreensão da aprendizagem de forma teórica. Isso, além da individualidade no âmbito pessoal e da liberdade de atuação pedagógica, é reflexo da formação leitora e docente que cada um recebeu.

Encontramos nas respostas dos professores universitários indícios que se aproximam do modelo Top-down, que prioriza o ato de ler sob o ponto de vista do leitor. Segundo Kato (1990) e Souza (2012), quando realizamos leituras diversas e com elas conseguimos inferir sobre os assuntos, torna-se possível acessar e rever os significados do código escrito aguçando a compreensão. Dentre os quarenta e oito respondentes, $31 \%$ dos professores parecem, entender a leitura dentro deste modelo. Como é possível perceber nos relatos: "Ler e compreender o que leu." (R 47) e leitura é "aprofundar em algum assunto." (R 41). Ler é também como relata o respondente (R 38) "transmissão de pensamento e conhecimento através de uma simbologia." Segundo Duran (2009) e Leffa (1996), neste modelo, quando lemos, dividimos os processos de informação, de forma fragmentada, tornando a compreensão de cada elemento, que faz parte de um todo, mais simplificada de ser processada pelo leitor.

Percebemos os traços de uma formação e, por consequência, a constituição de um conceito de leitura na visão do modelo Top-down no relato do professor (R 39), para quem ler "é o hábito de ler as obras disponíveis e de interesse, interpretando-as e, se possível, colocar em prática as lições aprendidas." De acordo com Duran (2009), na perspectiva do modelo Topdown, a leitura é um processo cognitivista, de modo que cada leitor é responsável pelo sentido do que lê, "uma vez que a leitura é permeada por sua bagagem adquirida previamente, pois é acessando essa bagagem que ele atribui significado ao texto." (DURAN, 2009, p. 06).

Diante essas declarações, retomamos que, segundo Tardif (2002), os saberes pedagógicos, constituem-se pelo domínio do conteúdo teórico do magistério, que é aprendido no processo de formação inicial, pelo exercício da prática pedagógica, pelo tempo de atividade profissional, pela experiência de mundo. Por esse motivo, é possível afirmar que tais saberes pedagógicos não são estáticos, nem são produzidos da mesma forma ou são sentidos e vivenciados com a mesma intensidade pelos professores. Abrangem uma infinita diversidade de questões, problemas e objetos que são relacionados às atividades cotidianas. Para o autor, os saberes docentes são plurais e heterogêneos; podem, portanto, sofrer alterações, pois estão submetidos às interferências políticas, pessoais e profissionais. Neste sentido, a forma de se posicionar quanto ao ensino de leitura, assumindo ou seguindo um modelo de leitura para si, vai interferir na forma como se lê e consecutivamente. No caso da docência, na forma metodológica atribuída a aprendizagem dos alunos.

Segundo os dados da pesquisa, 9\% dos professores universitários, a partir da resposta

à pergunta: $O$ que você entende por leitura? - conforme a nossa análise, possuem uma visão da leitura que correspondem, ao modelo Bottom-up. De acordo com Duran (2009), neste modelo o leitor analisa a disposição das informações de um texto, tais como estão dispostas. Dois 
exemplos estão presentes nestas falas: leitura é o "ato de decifrar as mensagens transmitidas pela escrita." (R 02) Leitura é "ler livros." (R 32). Essas expressões demonstram exatamente o que Duran (2009, p. 04) explica ser a visão no modelo Bottom-up, ou seja, o "[...] ato de defrontar-se com o material escrito e decodificar os sinais gráficos, em som articulado, em forma de palavras". Este é o tipo de leitura na qual o leitor busca a compreensão fragmentada, de modo que a compreensão ocorre de forma automática, porque "[...] uma vez que o leitor é capaz de decodificar, ele é automaticamente conduzido ao sentido dessa palavra, o que resultaria na imediata compreensão do texto escrito." (DURAN, 2009, p. 04). Por outro lado, podemos analisar que, para Versiani, Yunes e Carvalho (2012), como a leitura é um processo subjetivo, este pode ser considerado um processo inicial e essencial, no qual compreendemos o código. Finalizamos com o pensamento de Britto (2002, p. 32), para quem a leitura é "resultado ora da associação com o princípio da decifração, ora por derivação do princípio interpretativo." A compreensão da leitura, neste entendimento, abrange desde os processos iniciais que envolvem o ato de ler, como a codificação, até o posicionamento do leitor diante do texto e do contexto.

Outro fator influenciador na prática pedagógica, segundo Fischer (2006), é quando as pessoas aprendem a ler e descobrem o conhecimento, descobrem um mundo diferente. Neste sentido, ler constitui conhecer e reconhecer-se no mundo formando conceitos e opiniões, assim assegura Freire (2006). Tais opiniões podem apresentar posições críticas e reflexivas, já outras podem ser amparadas em opiniões comuns e corriqueiras. As posições, opiniões e os conceitos construídos pelos indivíduos, muitas vezes, são reflexos de pressuposições ou também reconstruções de opiniões de várias pessoas de uma comunidade e é isso que caracterizamos de senso comum. O que foi exposto ocorre com a conceituação da leitura no campo da docência. Dentre os respondentes, $12 \%$ representam algumas considerações quanto à leitura associadas a opiniões gerais, que remetem ao senso comum. Percebemos, dentre as análises, quatro respostas que consideramos apresentar essas noções. Como na expressão de que leitura é "tudo" (R 21) e em outra resposta a leitura é "viajar num mundo de conhecimento." (R 16). De acordo com os dados pesquisados e amparados em Freire (2006) e Souza (2012), quando estes professores, ao expressarem sua opinião sobre a leitura recaem no senso comum, é porque construíram seus conceitos com base no que vivenciam como leitores e não porque receberam uma formação específica sobre leitura.

Enfim, o que é leitura para os professores universitários? Percebemos com esta análise que a leitura dentro do contexto da docência universitária é um instrumento de ensino utilizado para todas as áreas do conhecimento. Contudo,nem todos os respondentes compartilham da mesma conscientização, talvez por falta de uma formação em leitura de forma mais técnica. Isso porque não temos um curso específico na docência do ensino superior que discuta sobre o ensino de leitura, em formato de especialização no assunto. Consideramos, portanto, conforme os apontamentos de Alliende e Condemarín (2005), que não existe uma divisão rígida nos tipos de leituras que realizamos. Elas nos exigem habilidades leitoras que irão nos aproximar com o texto, assim vamos apropriando-nos dos conceitos e os internalizando. Logo, isso, vai refletir nas organizações das metodologias da prática diária.

A leitura é um meio de aproximação entre os leitores e a produção cultural, "podendo significar a possibilidade concreta de acesso ao conhecimento e agudização do poder de crítica por parte do público leitor." (ZILBERMAN E SILVA, 2004, p. 112). De acordo com nossas análises, o ensino de leitura é uma atividade que estabelece uma relação de trocas de saberes entre professores e alunos. Um dos professores deixa claro isso: "como sou advogado e estou professor, tenho que procurar práticas contextuais que me permita chegar até o aluno (a) de uma maneira compreensível e didática." (R 35). Outro professor diz: "através da leitura vou 
montando minhas aulas e vou passando para meus alunos." (R 39). "Ao aprofundar nossos conteúdos, posso verificar se o acadêmico realmente faz leituras aprofundadas ou se memoriza ou se vale de leituras superficiais." (R 40). Ao analisarmos estes depoimentos, amparamo-nos em Souza (2012) e notamos que, quando o professor é um leitor assíduo, consegue estabelecer uma relação de troca de conhecimentos com o aluno, por meio de sua bagagem leitora e assim avaliar e melhorar a aprendizagem. É a partir desse entendimento que discutimos a prática.

Por isso, consideramos que a prática pedagógica na docência do ensino superior é um campo formado por vários elementos e aspectos que envolvem os saberes e conhecimentos da docência, pois, conforme um dos respondentes, "somos fruto do que aprendemos e da busca constantemente de ensinar." (R 36). Inferimos com Cunha (2010b, p. 22) que "[...] o processo de ensinar, em que são mobilizados saberes indicativos da complexidade da docência, envolve uma complexidade de docência." Portanto, as experiências adquiridas na docência ligada aos estudos ordenados dentro e fora da área de atuação, muitas vezes entrelaçados às leituras que os professores realizam, apontam significativas diferenças na prática. Percebemos neste estudo e na opinião dos professores, que suas leituras auxiliam no desenvolvimento de sua profissão, pois um deles assim se manifesta sobre a leitura: "na minha área profissional faz a diferença na prática pedagógica, por meio de discussões sobre aspectos teóricos e práticos do conteúdo a ser dado.” (R 24). Desse modo, dentro do contexto da complexidade da ação docente, pensou-se nas influências que a formação leitora provoca no ensino superior, pois "ler ensina a ter uma visão mais crítica do mundo, auxilia na didática, na eloquência e na argumentação." (R 13). Foi, também, por meio dessas percepções dos professores universitários, que realizamos as reflexões acerca do desenvolvimento do ensino de leitura em sala de aula no âmbito universitário.

Dessa mesma forma, relacionamos a formação com a leitura. Lembramos o apontamento de Nóvoa (1992) de que a formação e a construção da identidade docente não se constituem apenas pela unificação dos conteúdos, nem das metodologias ou das técnicas, mas sim por um conjunto de saberes e elementos que unidos as constituem. Assim, durante a prática docente deve-se ter interação de todos os saberes, inclusive na forma na qual nos relacionamos com a leitura, que envolve todos os conhecimentos e dessa forma nos constituímos leitores. De acordo com as pesquisas de Cunha (2012), não existe uma única e exclusiva pedagogia universitária, ou um único e exclusivo modo de atuar na educação. $\mathrm{O}$ que fortalece a qualidade tanto da educação quanto da docência são o conjunto de saberes pedagógicos dos professores, os conhecimentos teóricos e práticos, as experiências profissionais e vivenciais, as pesquisas. Isto é, segundo a autora, existem várias "pedagogias de ensino", que constituem a profissionalização docente. Neste parâmetro, consideramos que, na dimensão da docência universitária, não há uma fórmula única de ensinar e aprender, tampouco um roteiro com metodologias prontas a seguir como um manual pedagógico. Cabe a cada professor se reconhecer professor e assumir sua identidade profissional.

A formação leitora implica tanto na prática pedagógica quanto na sociedade, pois a leitura também é considerada um ato social, porque ler, em certa medida, provoca transformações sociais, devido à aquisição do conhecimento. As pessoas leem e são envolvidas em um contexto sociocultural que envolve a produção e a recepção de textos, imagens e sons, proporcionando condições de reflexões sobre todo tipo de assunto. Por isso, também, que damos a devida importância de o professor ter uma formação leitora e uma posição de conceituação teórica de leitura. (KLEIMAN, 2009; KOCH E ELIAS, 2006; LAJOLO, 1999; SOARES, 2004).

$\mathrm{Na}$ tentativa de conceituar a leitura, de acordo com a pesquisa, os professores atribuem benefícios que a leitura proporciona em suas vidas pessoais e profissionais. Verificamos, 
portanto, por meio das percepções e reflexões da prática pedagógica que as leituras realizadas pelos professores proporcionam mais autonomia, criatividade, melhora a leitura, aumenta a criticidade, ajuda no desenvolvimento do poder de discurso, dá maior domínio ortográfico, sintático e semântico. Diante do exposto, concluímos com as amostras que os professores possuem uma formação leitora proficiente. As questões relativas às atribuições de seus conceitos de ensino de leitura não são técnicas, são proporcionais com as visões de leitores assíduos. O fato é que cada pessoa atribui por meio de suas experiências e formação o que significa a leitura. Isso é um fator que não interfere diretamente na análise de constituir ou evidenciar um conceito, entretanto, as concepções e o entendimento da leitura de forma mais técnica e teórica elevaria a qualificação da formação docente. Logo, pensamos que seria de bom tom ter um curso de aperfeiçoamento de ensino de leitura voltado à docência no ensino superior.

\section{Considerações finais}

Formular ou determinar qualquer conceito por meio da percepção de outrem não é a consolidação e tão pouco a estagnação de um produto único, acabado ou exato, mas é um olhar, uma interpretação. Por isso, existe a ciência e a pesquisa. Compartilhamos o conhecimento, investigamos e nos amparamos nos resultados, para assim aprimorar a aprendizagem e avançar no conhecimento. Conceituar leitura não é uma tarefa fácil. Identificamos que a formação docente e leitora não é um processo homogêneo e constitui-se por meio da reflexibilidade crítica sobre a própria prática pedagógica e por intermédio da reconstrução contínua da identidade cultural de cada professor.

Concluímos, em conformidade com Leffa, que a leitura é um processo cognitivo e metacognitivo, interativo de compreensão da realidade do mundo no qual fazemos parte. Segundo Leffa (1996), a leitura não se dá por acesso direto a essa realidade, e sim por intermediação de vários elementos fragmentados da realidade. Podemos considerar, portanto, que a leitura, embora seja o resultado da compreensão do código escrito e da representação de uma língua, não se limita ao processo de decifração. Nesse sentido, a pesquisa apontou que a leitura é uma ferramenta interdisciplinar de trabalho e de produção de conhecimentos, sentidos e significados. E o ato de ler é uma competência a ser adquirida, assim como a assimilação dos métodos pedagógicos abordados por esse processo. Para os $48 \%$ dos professores participantes, a leitura é sinônimo de compreensão, de aprendizado contínuo, de renovação intelectual, de aquisição de conhecimento e um mecanismo de satisfação pessoal. Percebemos diante das respostas o que Soares (2004) afirma: as pessoas leem em comunidade, envolvidas em um contexto sociocultural que abrange a produção e a recepção de textos, proporcionando condições de reflexões sobre todo tipo de assunto. Este posicionamento é defendido também por Koch e Elias (2006) e Lajolo (1999), assegurando que ler é, em certa medida, um ato de transformação e conhecimento. Por meio da leitura, as pessoas se modificam e essa mudança é refletida na sociedade. Para chegar nessas inferências, amparamo-nos também nas pesquisas dos autores Carrell; Devine; Eskey (1988), Rumelhart (1977) e Stanovich (1980), pois nossos resultados condizem com os seus estudos sobre linguagem, leitura e escrita. Segundo os autores, o ato de ler faz parte de um processo interativo, mental, cognitivo e metacognitivo, relacionado aos esquemas mentais-(schemata), que, por sua vez, são acionados pelo conhecimento prévio, pela memória e as lembranças de cada indivíduo.

Neste sentido, entendemos que a formação do professor e seus saberes docentes, assim como sua própria reflexão, percepção e conceitualização quanto à leitura e seu ensino, são fatores primordiais, que influenciam na prática pedagógica. Tais fatores e os professores caracterizam-se como importantes agentes, responsáveis pelo aprendizado e formação de seus 
alunos. De acordo com nossos estudos, a formação leitora é intrínseca no saber e fazer pedagógico, uma vez que a leitura faz parte da constituição dos sujeitos e da docência. Neste contexto, a leitura vista como uma competência a ser adquirida, que promove a criticidade e a emancipação dos sujeitos e entrelaça-se a constituição formação docente e leitora, reforçando a identidade profissional do professor universitário, como visto em Nóvoa (1992) e Vasconcelo (2000). Concluímos este pensamento lembrando que os saberes dos professores são fatores primordiais e influenciadores na questão de suas formações. Conforme Tardif (2002) afirma, os "saberes" docentes caracterizam as ações, as ideias, pensamentos, juízos, argumentos e discursos docentes, que, por sua vez, obedecem às exigências de racionalidade no ato de educar.

Com relação às práticas pedagógicas, a pesquisa distinguiu que o processo de formação leitora é um fator influenciador nos quesitos de metodologias de ensino aprendizagem também no ensino superior. Segundo Leffa (1996), para se alcançar uma leitura eficiente e uma formação proficiente em leitura, os conhecimentos prévios e bagagem literária do leitor devem ser levados em consideração e é de suma importância serem acionados, porque cada leitor atribui uma visão diferente de mundo. Concluímos com a pesquisa que a atuação pedagógica em leitura dos professores universitários frente à formação dos alunos, no processo de ensino e aprendizagem, é de suma importância. As questões como seu posicionamento na prática educativa, sua concepção de leitura e a utilização dos modelos de leitura no desenvolvimento das atividades, refletem e influenciam na aprendizagem. Por isso, que os educadores são essenciais e seu papel na educação insubstituível. Logo, a ação pedagógica deve ser direcionada para a produção do conhecimento do aluno e a devida orientação neste processo, mesmo com toda e qualquer tecnologia, a responsabilidade e o compromisso com a aquisição do conhecimento, são dos educadores e dos educandos.

O exercício do magistério demanda aceitar riscos e desafios, ter posição e consciência crítica e ética. Souza (2012) diz se os educadores não sabem ler, como vão ensinar leitura? E Nóvoa (1992) que se deve atentar para identidade profissional e pessoal de cada professor, como agente de suas escolhas. Com Freire (2002), lembramos que somos seres inacabados. Logo, o ponto essencial que está presente nestas reflexões é a formação continuada de professores em qualquer nível de ensino. Essas questões passam pela revisão constante dos educadores, de seu papel enquanto formador, de reflexão sobre sua formação contínua e sobre suas práticas pedagógicas. Por fim, podemos dizer que o estudo apontou que a formação leitora que cada professor recebeu interfere tanto na vida profissional quanto na vida pessoal dos pesquisados. Esperamos com este artigo suscitar mais reflexões quanto ao ensino de leitura e aumentar debates em torno do assunto.

\section{Referências}

ALLIENDE, F; CONDEMARÍN, M. A leitura: teoria, avaliação e desenvolvimento. Tradução de Ernani Rosa. Porto Alegre: Artmed, 2005.

BARDIN, L. Análise de conteúdo. 3. ed. Lisboa: Edições 70, 2004.

BRITTO, L. P. L. Inquietudes e Desacordos: a leitura além do óbvio. Campinas: São Paulo, Mercado de Letras, 2012.

CARRELL, P., DEVINE, J., \& ESKEY, D. (ed.). Interactive approaches to second language reading. New York: Cambridge University Press, 1988. 
CUNHA, M. I. A docência como ação complexa. In: CUNHA, M. I. (org.). Trajetórias e lugares de formação da docência universitária: da perspectiva individual ao espaço institucional. Araraquara, SP: Junqueira \& Marin; Brasília, DF: CAPES; CNPq, 2010b.

CUNHA, M. I. Prefácio. In: SOUZA, A. R. B. de; SARTORI, A. S.; NORONHA, E. C. S. F. (org.). Formação docente e práticas pedagógicas: cenários e trajetórias. Florianópolis: UDESC, p. 09-12, 2010a.

CUNHA, M. I. Prefácio. In: VOLPATO, G.; PINTO, M. M. (org.). Pedagogia universitária: olhares e percepções. Curitiba, Paraná: CRV, p. 07-09, 2012.

DURAN, G. R. As concepções de leitura e a produção do sentido no texto. Revista Prolíngua. Paraíba, v. 04, n. 02, 01 Jul./Dez. 2009. p. 01-14. Semestral. ISSN 1983-9979. Disponível em:

<http://www.periodicos.ufpb.br/ojs/index.php/prolingua/article/view/13427/7623> Acesso em: 10 mar. 2019.

ESKEY, D.E. Holding in the bottom: An interactive approach to the language problems of second language readers. In: CARRELL, P., DEVINE, J., \& ESKEY, D. (ed.). Interactive approaches to second language reading. Cambridge: Cambridge University Press, 1988.

FISCHER, S. R. História da leitura. Tradução de Claudia Freire. São Paulo: UNESP, 2006.

FREIRE, P. A importância do ato de ler: em três artigos que se completam. São Paulo: Cortez, 2006.

FREIRE, P. Pedagogia da autonomia: saberes necessários à prática educativa. 25. ed. Rio de Janeiro: Paz e Terra, 2002.

GIMENO SACRISTÀN, J. Conciencia y acción sobre la práctica como liberación profesional. In: IBERNON, F. (coord). La formación permanente del profesorado en los países de la CEE. Barcelona: ICE/Universitat de Barcelona: Horsori, 1993.

KATO, M. O aprendizado da leitura. 4. ed. São Paulo: Martins Fontes, 1990.

KLEIMAN, A. Texto e leitor: aspectos cognitivos da leitura. Campinas: Pontes, 2009.

KOCH, I. V; ELIAS, V. M. Ler e compreender: os sentidos do texto. São Paulo: Contexto, 2006.

LAJOLO, M. Do mundo da Leitura para a Leitura do Mundo. Ática, 5. ed. São Paulo, 1999.

LEFFA, J. V. Aspectos da leitura: uma perspectiva psicolinguística. Porto Alegre: Sagra Luzzatto, 1996. (Coleção Ensaios, 7).

MASETTO, M. (org.). Docência na universidade. Campinas: Papirus, 1998. 
NÓVOA, A. Os professores e as histórias da sua vida. In: NÓVOA, A. (org.). Vidas de professores. Porto: Porto Editora, 1992.

RUMELHART, D. E. Toward an interactive model of reading. In: DORNIC, S. (ed).

Attention and performance UL. Nova Iorque: Academic Press, p. 573-603,1977.

SILVA, E. T. O ato de ler: fundamentos psicológicos para uma nova pedagogia da leitura. São Paulo: Cortez, 1981.

SOARES, C. Docência universitária: implicações da formação leitora dos professores na prática pedagógica. 2019. 133 f. Dissertação (Mestrado) - Curso de Mestrado em Educação, Programa de Pós-graduação em Educação, Universidade do Extremo Sul Catarinense- Unesc, Criciúma, 2019. Cap. 6.

SOARES, M. B. As condições sociais da leitura: uma reflexão em contraponto. In: ZILBERMAN, R.; SILVA, E. T. Leitura: perspectivas interdisciplinares. São Paulo: Ática, p. 18-29, 2004.

SOLÉ, I. Estratégias de leitura. Porto Alegre: Artmed, 1998.

SOUZA, A. C. Cognição, Aprendizagem e Língua. Parte I. In: SOUZA, A. C.; GARCIA, W. A. C. A produção dos sentidos e o leitor: os caminhos da memória. Florianópolis: NUP/CED/UFSC, 2012. p. 21-105.

TARDIF, M. Saberes docentes e formação profissional. Petrópolis-Rio de Janeiro: Vozes, 2002.

VASCONCELO, M. L. M. C. A formação do professor do ensino superior. 2. ed. São Paulo: Pioneira, 2000.

VERSIANI, D. B; YUNES, E.; CARVALHO, G. Manual de reflexões sobre boas práticas de leitura. São Paulo: UNESP, 2012.

ZABALZA, M. A. O ensino universitário: seu cenário e seus protagonistas. Porto Alegre: Artmed, p. 239, 2004.

ZILBERMAN, R.; SILVA, E. T. Leitura: por que a interdisciplinaridade? In: ZILBERMAN, R.; SILVA, E. T. Leitura: perspectivas interdisciplinares. São Paulo: Ática, p. 11-17, 2004.

Recebido em janeiro de 2020.

Aprovado em maio de 2020. 